\title{
AN EXPERIMENTAL STUDY
}

\section{ON THE INFLUENCE OF DARKENING MATERIALS ON RADIATION AND MELTING RATE ON AN ICE-SNOW SURFACE AND THE RESULTS OF THEIR PRACTICAL APPLICATION}

\author{
Abstract \\ by \\ Bai Zhongyuan, XiE Zrchu and Ding Lianfu \\ Lanzhou Institute of Glaciology and Cryopedology, Academia Sinica, Lanzhou, Gansu, \\ People's Republic of China
}

The vast irrigated region in arid basin of Northwest China periodically suffers from insufficiency of water resources. Hence study on the artificial regulation of ice and snow melting will be of great practical importance for agricultural production. During 1958-77, experimental investigations were carried out on the influence of darkening material on melting intensity and radiation balance on ice-snow surfaces. Results of field investigations and artificial dusting of glaciers and stream icing in the mountainous regions of Northwest China, carried out by the Chinese Academy of Sciences, are summarized.

(1) Dusting effectiveness, using various albedo-reducing materials, appears mainly as a decrease in albedo and depends on the colour, specific weight (r), particle diameter (d) and rate of dusting $(G)$ of the material used. In spring or autumn coal dust and carbon-black applied to a snow surface at a rate of $50-100 \mathrm{gm} / \mathrm{m}^{2}$ decreased albedo by $54 \%$ and $45 \%$, effecting a net increase of radiation balance at $76.5 \%$ and $140 \%$. In the summer, during intensive ablation, the effective radiation decreases with the increase in the rate of dusting. Spreading of darkening materials on the augeis ice gives similar results.

(2) As the rate of dusting increases, the radiation effect tends towards a limit value, probably governed by the variation of albedo of the dusted surface. Hence, various dusting materials all have their most effective rate of dusting, such as $5 \mathrm{gm} / \mathrm{m}^{2}-10 \mathrm{gm} / \mathrm{m}^{2}$ for carbon-black, $50-70 \mathrm{gm} / \mathrm{m}^{2}$ for coal-dust, $160-200 \mathrm{gm} / \mathrm{m}^{2}$ for plant-ash, 250-300 $\mathrm{gm} / \mathrm{m}^{2}$ for black soil, $300-350 \mathrm{gm} / \mathrm{m}^{2}$ for moraine soil, $3500-4000 \mathrm{gm} / \mathrm{m}^{2}$ for debris of granite.

(3) Through computation and analysis of the effect of darkening on radiation and meltwater, we have found that the change of intensity of melting is determined at the first approach by the changes of albedo and effective radiation., heat output (from 56.4-97.0\%, mean about $83.9 \%$ ), while evaporation only $15.8 \% \quad(3.0-41.5 \%)$. On higher slopes, aridity of the glacier climate increases, evaporation increases gradually and melting decreases. In the arid mountainous region, high evaporation is important in mass balance and provides the foundations for glacial nourishment.

(4) When the glacier is covered with a debris layer, constitution of the heat budget takes another form. The heat consumed in ablation decreases to $20-40 \%$, the rest being consumed in evaporation and in diffusion into the adjacent layer of air by turbulent exchange.

Differences in the variations of heat balance mainly relate to topography (including direction and angle of the slopes of glacier, screening effect of the mountains, etc) and albedo for advanced studies; we take the No 1 Glacier of Ürümqi River, Tianshan mountains as an example. The spatial distribution and time history of albedo and radiation over the glacier surface have been carefully estimated and charts of variations in distribution drawn. Calculations presented here show that the screening effect of the mountain, and differences in heat balance, are very important to the maintenance of glaciers in particular valleys and explain why, at the same time, other places at similar altitudes are without glacier development.

\section{SNOW MOISTURE METERS}

\section{Abstract}

by

\section{A. DENOTH AND A. FogLeR}

Department of Physics, University of Innsbruck, Austria

Various instruments and techniques for the determination of snow wetness, for example calorimeters, centrifuges, chemical devices, dielectric devices and also tensiometers are in use. Problems in measuring the liquid water content with these techniques are discussed by Colbeck (1978). Dielectric measuring methods of liquid water content in snow make use of the large difference between the relative permittivity of ice (3.15) and of water (87.7) in the high-frequency regime. Various dielectric devices using air gap condensers and open resonators have been tested and compared recently (Denoth and others 1984). Here, new developments of dielectric sensors with operating frequencies in the range of $10 \mathrm{MHz}$ to $1 \mathrm{GHz}$ are presented: a plate condenser, a cylindrical condenser, a coaxial sample holder and a monopole antenna were used as sensors to measure the average dielectric constant in a snow volume of approximately $1000 \mathrm{~cm}^{3}$; a flat condenser in strip-line 
technique - which is the two-dimensional analogon of the plate condenser - was used as sensor for measuring the dielectric constant of thin snow layers. A sensor consisting of a combination of two flat condensers has also been developed. The geometry (spacing and width of the two coplanar conducting stripes) has been designed to allow the measurement of the vertical gradient in the dielectricl properties of a snow cover (Foglar 1983). The sensor is operated at $27 \mathrm{MHz}$. Neglecting the effects of snow texture and liquid water distribution, the dielectric constant of snow is a linear function of density and a quadratic function of the volumetric water content (Denoth and others 1984): snow wetness can, therefore, be calculated from the measured dielectric constant and the snow density.
The Austrian "Fonds zur Forderung der wissenschaftlichen Forschung" is thanked for supporting these developments through Grant nos 3888 and 4525 .

\section{REFERENCES}

Colbeck S C 1978 The difficulties of measuring the water saturation and porosity of snow. Journal of Glaciology 20(82): 189-201

Denoth A, Foglar A, Weiland P, Matzler C, Aebischer H, Tiuri M, Sihvola A 1984 A comparative study of instruments for measuring the liquid water content of snow. Journal of Applied Physics (in press)

Foglar A 1983 Entwicklung eines Schneefeuchte-Megerates zur wassergehaltsbestimmung in dunnen Schichten. Diploma Thesis, Institute of Experimental Physics, University of Innsbruck, Austria

\title{
HEAT BALANCE OF A MARITIME GLACIER IN GONGGA MOUTAINS, AND A DISCUSSION OF IMBALANCE
}

\author{
Abstract \\ by \\ HAN YUAN-JIE \\ Lanzhou Institute of Glaciology and Cryopedology, Academia Sinica, Lanzhou, Gansu, \\ People's Republic of China
}

The author observed and analysed all terms of glacier heat budget at four altitudes and on three kinds of surface, in three glaciers of the Gangga Mountains during the ablation season (April to August 1983), and recognised that the Gongba Glacier was a quasi-maritime glacier. The radiation term $Q_{b}$ was primary heating. It reached 400-800 $\mathrm{cal} / \mathrm{cm}^{2}$.day (mean value about $>80 \%$ ). The sensible heat transfer term $Q_{S}$ was not so high as in other maritime glaciers, such as Ivory Glacier and McCall Glacier. Maximum values of $\mathrm{Q}_{\mathrm{S}}$ reached $40 \%$ (moraine), $30 \%$ (moraine mixed with ice), and $9 \%$ (ice). Ablation term $\mathrm{Q}_{\mathrm{a}}$ was the same as other maritime glaciers: $94.5 \%$ (ice) and $50 \%$ (moraine mixed with ice). The feature was near to the middle Ronbuk Glacier, in the Himalayas. Its imbalance was large and near to that of the McCall Glacier.

In this study, by means of heat budget estimation on the three sorts of glacier surface, we found that there were two feedback processes relating respectively to horizontal turbulence and ablation permeation. Horizontal turbulence on the moraine induced heat energy diffusion or dispersion and therefore protected the glacier from ablation. The process was a negative feedback. Ablation permeation on the ice surface brought surface heat energy to the deep ice levels, simultaneous to heat the porous and crack ice environment and further to split it. This was another positive feedback.

Thus two feedbacks caused two kinds of heat budget imbalance. On the moraine surface of the Small Gongba Glacier, the imbalance reached -65 to $-158 \mathrm{cal} / \mathrm{cm}^{2}$.day $(14 \%-29 \%)$. On the moraine mixed with ice surface of Big Gongba Glacier, it reached -70 to $-161 \mathrm{cal} / \mathrm{cm}^{2}$.day $(8 \%$ - $18 \%$ ). But for the Hailogou Glacier, on a similar surface, it was between 0 and $36 \mathrm{cal} / \mathrm{cm}^{2}$.day $(6.8 \%)$.

To measure horizontal turbulence and permeation directly is very difficult. We estimated the quantity of heat brought by horizontal eddy exchange, for the nonuniform (moraine) surface, indirectly by means of differential of $\mathrm{Q}_{c}$ (conduction) ie $\Delta Q_{c}$. We also calculated the quantity of heat brought by permeation indirectly; from the vertical gradient of $\mathrm{Q}_{\mathrm{c}}$, ie $d \mathrm{Q}_{\mathrm{c}} / d \mathrm{z}$, for the uniform surface (ice, or moraine mixed with ice).

With dimension analysis, we found the heat balance equation for the nonuniform moraine surface had this form:

$$
d \mathrm{~T} / d \mathrm{t}=\mathrm{Q}_{\mathrm{b}}+\mathrm{Q}_{\mathrm{c}}+\mathrm{Q}_{\mathrm{a}}+\mathrm{Q}_{\mathrm{sz}}+\mathrm{Q}_{\mathrm{sl}}+\mathrm{Q}_{\mathrm{lz}}+\mathrm{Q}_{\mathrm{ll}}
$$

where $d \mathrm{~T} / d \mathrm{t}=$ moraine temperature varing, $\mathrm{Q}_{\mathrm{b}}=$ net radiation flux, $\mathrm{Q}_{\mathrm{c}}=$ conduction heating, $\mathrm{Q}_{\mathrm{a}}=$ ablation, $\mathrm{Q}_{\mathrm{SZ}}$ $=$ vertical sensible heating, $\mathrm{Q}_{\mathrm{Sl}}=$ horizontal sensible exchange, $\mathrm{Q}_{1 \mathrm{z}}=$ vertical latent heating, $\mathrm{Q}_{11}=$ horizontal latent exchange.

On the ice and moraine-mixed-with-ice-surfaces equation (1) becomes:

$$
0=Q_{b}+Q_{c}+Q_{a}+Q_{s}+Q_{l z}
$$

When $Q_{a}$ is measured by ablational run-off, the ablation permeation is always to be ignored. But it has a very important role in the heating of deep ice levels, and in particular on deep snow levels. Hence equation (2) must be used with care in describing the moraine surface heat budget of glaciers, as it may induce a large imbalance. Vice versa, we can use the imbalance to predict the morainize and ablational intensify.

Finally, with a view of thermodynamic theory, the entropy of glacier system is proportional to $\mathrm{T}^{3}$ of the system; there the glacier is a dispersional structure. According to Prigogine's theory the glacier varies from balance to imbalance and of course a heat balance equation showing imbalance is reasonable. However the imbalance is except of artificial error, that is our stand. 